\title{
Percepciones de los expedicionarios virreinales sobre el manejo indígena de territorios y recursos del norte de la Patagonia a fines del siglo XVIII
}

\author{
Laura Aylén ENRIQUE \\ Universidad de Buenos Aires \\ aylenle@yahoo.com.ar
}

Recibido: 8 de diciembre de 2010 / 15 de febrero de 2012

Aceptado: 21 de marzo de 2012

\begin{abstract}
RESUMEN
A fines del siglo XVIII las autoridades borbónicas ordenaron realizar expediciones en el interior de ciertos territorios coloniales que consideraban bajo su dominio aunque sólo conocían de ellos las costas. Los diarios de viaje de los funcionarios virreinales enviados al norte de la Patagonia nos permiten analizar sus interpretaciones sobre los grupos indígenas que habitaban la región y el manejo del territorio y los recursos que éstos hacían. Consideramos que las percepciones y los usos sobre el paisaje de los expedicionarios evidenciaban las luchas de poder por otorgar sentido al territorio y se encontraban estrechamente ligados a las representaciones que los viajeros se formaban sobre los «otros». Los hispanocriollos interpretaban los modos en que los indígenas utilizaban el territorio y determinados recursos condicionados por el escaso conocimiento que tenían sobre el paisaje en contraposición con el manejo que los indígenas daban al mismo.
\end{abstract}

Palabras clave: Uso del paisaje, Patagonia septentrional, indios patagónicos, expediciones, siglo XVIII.

\section{Perceptions of the Members of Viceregal Expeditions on the Indigenous Management of Territories and Resources of the North of the Patagonia by the End of the $18^{\text {th }}$ Century}

\begin{abstract}
At the late eighteenth century Bourbon authorities ordered expeditions towards the interior of certain colonial territories of which only the coasts were known but they were considered to be under their domain. The trip diaries of the colonial officials sent to northern Patagonia allow us to analyze their interpretations on the indigenous groups that inhabited the region and the management of the territory and resources they did. We think that perceptions and uses of the landscape of the expedition evidenced the power struggles to make sense of territory and were closely linked to the representations that travelers were on the «others». The Hispanic-creoles interpreted the ways in which Indians used the land and certain resources conditioned by the limited knowledge that they had about the landscape, in contraposition with the management of the landscape by the natives.
\end{abstract}

Key words: Use of the landscape, Northern Patagonia, Patagonian Indians, expeditions, 18th century.

Sumario: 1. Introducción. 2. Territorios en disputa. 3. El manejo indígena del territorio desde la perspectiva hispanocriolla. 4. Influencias en los usos del territorio por parte de indígenas y expedicionarios. 5. Consideraciones finales. 6. Referencias documentales. 7. Referencias bibliográficas.

\section{Introducción}

A finales del siglo XVIII, la Corona española, interesada en incrementar el control de sus colonias como consecuencia de las políticas borbónicas en América, ordenó 
realizar una serie de expediciones al norte de la Patagonia. Las autoridades coloniales intentaban así reconocer el territorio y establecer y/o fortalecer relaciones «amistosas» con los indígenas que habitaban y controlaban en esa época dicha región. La zona era también importante para los hispanocriollos debido a que las sierras de la Ventana se habían conformado como un centro de intercambio interétnico y de cría de ganado, y las Salinas Grandes en un núcleo de extracción de sal que abastecía el comercio indígena y los requerimientos alimenticios de las ciudades. Además, esas regiones se conectaban económicamente con Buenos Aires, Chile y los tehuelches.

Con el objeto de mejorar la administración del Virreinato del Perú -que resultaba demasiado extenso-, Carlos III creó en 1776 el Virreinato del Río de la Plata, nombrando a Buenos Aires como su capital. Poco después mandó fundar el Fuerte de Nuestra Señora del Carmen (1779) en la desembocadura del río Negro, como punto de avance hacia los territorios dominados por grupos indígenas insumisos. Envió también funcionarios virreinales a reconocer los territorios pampeano y patagónico - de los que sólo se conocían las costas-que registraron sus impresiones en diarios de viaje e informes. Consideramos que las representaciones de los viajeros, plasmadas en la documentación, muestran la forma en que percibían a los habitantes, las luchas de los diversos grupos por otorgar sentido a los territorios y el conocimiento desigual del territorio que tenían los hispanocriollos y los grupos indígenas.

Por ello hemos analizado, desde una perspectiva etnohistórica, los modos en que los expedicionarios de fines del siglo XVIII interpretaban el manejo indígena de los recursos y los territorios norpatagónicos. Dado que las fuentes documentales se refieren a lugares y épocas semejantes, hemos realizado un cruzamiento de los datos que nos ha permitido comprender las interacciones entre los actores sociales de un modo más integral ${ }^{1}$.

\section{Territorios en disputa}

En primera instancia, es preciso reconocer los diversos actores sociales que participaban en las interacciones con los expedicionarios, para lo que hemos considerado tanto los estudios de Nacuzzi (1998, 2007, 2008), quien ha profundizado en la heterogeneidad de los grupos indígenas, como los aportes de Barth (1976) sobre la identidad. Al respecto observamos cómo, al caracterizar a los indígenas, las descripciones de los viajeros de fines del siglo XVIII enfatizaban la idea de salvajismo. En este sentido coincidimos con Irurtia (2002) sobre la dificultad de reconstruir la perspectiva indígena desde los documentos existentes.

Además, resulta relevante abordar las negociaciones políticas y sociales entre indios y blancos, prestando atención a los roles activos que asumían los miembros de ambos grupos en interacción, ya que los indígenas también «adoptaron y/o adaptaron diversos bienes, negociaron, intercambiaron, brindaron y exigieron servicios a 'los blancos' en una relación bastante igualitaria» (Nacuzzi 2007: 222). Así, pensamos las

1 Esta complementariedad entre las fuentes trabajadas fue abordada ya en trabajos previos (Enrique 2010a, 2010c). 
fronteras como espacios de negociación y resistencia, donde los usos y representaciones del paisaje reflejaban las relaciones de poder entre los grupos (Enrique 2010b). Retomamos la idea de Boccara (2005) de que al implementarse ciertos «dispositivos de poder» normalizadores (Foucault 1992), se generó un nuevo orden cognoscitivo para reconocer y territorializar. Asimismo, resulta interesante la distinción de Bayón y Pupio (2003) entre los modos de organizar los espacios adoptados por las sociedades indígenas y «blancas» definidos en las interacciones. Dichas autoras han estudiado la situación de la región en la segunda mitad del siglo XIX, planteando que las sociedades indígenas y la nacional tenían «lógicas distintas de conceptuar la organización del espacio y del territorio» (Bayón y Pupio 2003: 347). Hallamos relevante la distinción de las autoras entre la «organización espacial» y el «territorio» en relación con su afirmación de que las sociedades estatales, a diferencia de las indígenas nómadas, utilizaban líneas límite para definir sus territorios -buscando salvaguardar la tierra-. Al respecto, Quijada (2002a) ha señalado que los conflictos se originaban en torno a la tenencia del espacio más que por cuestiones de soberanía, y que las fronteras que esbozaban los hispanocriollos eran compatibles con la visión de los indígenas, quienes empleaban un sistema de permisos para transitar «territorios ajenos». En este sentido, abordamos la construcción conjunta de los límites territoriales a través de las negociaciones entre los distintos grupos y las diversas estrategias desarrolladas tanto por los expedicionarios como por los indios para obtener ventajas con respecto a los otros, en particular con respecto al paisaje.

Reflexionamos sobre los modos en que los hispanocriollos comprendían el uso de los recursos y el territorio llevado a cabo por los indígenas, teniendo en cuenta las formas en que los expedicionarios lo expresaban en los documentos: localizando a los caciques, a las agrupaciones y a los elementos clave en el paisaje. En relación con esto, Nacuzzi (1998) advirtió que, para describir a los indígenas, los etnógrafos tendieron a considerar fuentes de distintos períodos y lugares, por lo que ciertos geónimos se convirtieron progresivamente en gentilicios. Por ejemplo, los 'pehuenches' debían su nombre al consumo que hacían del fruto del pehuén -árbol autóctono de la zona del Neuquén que ocupaban- y los 'ranculches' o 'ranqueles' recibían esa denominación por habitar un área provista de abundante rancul -carrizo de las Pampas-. Nacuzzi (1998: 243) señaló también el sentido de otros apelativos: «"pampas’ (por la región que ocupaban), 'aucas' (por indio 'rebelde' o 'alzado', al menos en la región pampeano-patagónica), 'tehuelche' (del araucano: gente 'brava' o 'arisca') $\rangle^{2}$. Además, en los distintos documentos analizados, los funcionarios y viajeros describían de maneras diferentes a los grupos indígenas, sus caciques y localizaciones respectivas. Esto puede explicarse teniendo en cuenta el grado de conocimiento acerca de los mismos que cada uno de ellos tenía, tal como ha advertido Nacuzzi (1998) para el caso de Francisco de Viedma, quien habría abandonado progresivamente el término «pampas» al conocer mejor a los grupos con los que interactuaba ${ }^{3}$. Ejemplo de esto

\footnotetext{
2 Según Nacuzzi (1998), para los españoles, los grupos de sierra de la Ventana serían «pampas» o «aucas»; no obstante, para los indios, «auca» aludiría al peligro que esa gente representaba para los españoles, y serían los amigos del cacique Calpisqui del oeste de las sierras.

3 Nacuzzi (1998) destacó la asociación entre determinados caciques y ciertos grupos indígenas realizada por cada funcionario en relación con los vínculos que mantenían con ellos. Según dicha autora, los funcio-
} 
se observa en un diario de Viedma de 1781 en el que expresaba que las tolderías de Calpisquis y Guchulap -ubicadas en las sierras de Casuati-Tandil, Volcán y Salinas, con «permanente domicilio en las márgenes e inmediaciones del río Negro» (Viedma 1938b: 531)- estaban compuestas:

«de diferentes tribus, o naciones como las de los Chulilaquits, la de Quiliner, y así de otras naciones, cuyos nombres no le he podido comprender, bien me dijo había otro Cacique poderoso llamado Sn Quil, el que había de ir a visitarle con el Cacique Negro, dentro de pocas lunas» (Viedma 1938b [1781]: 531).

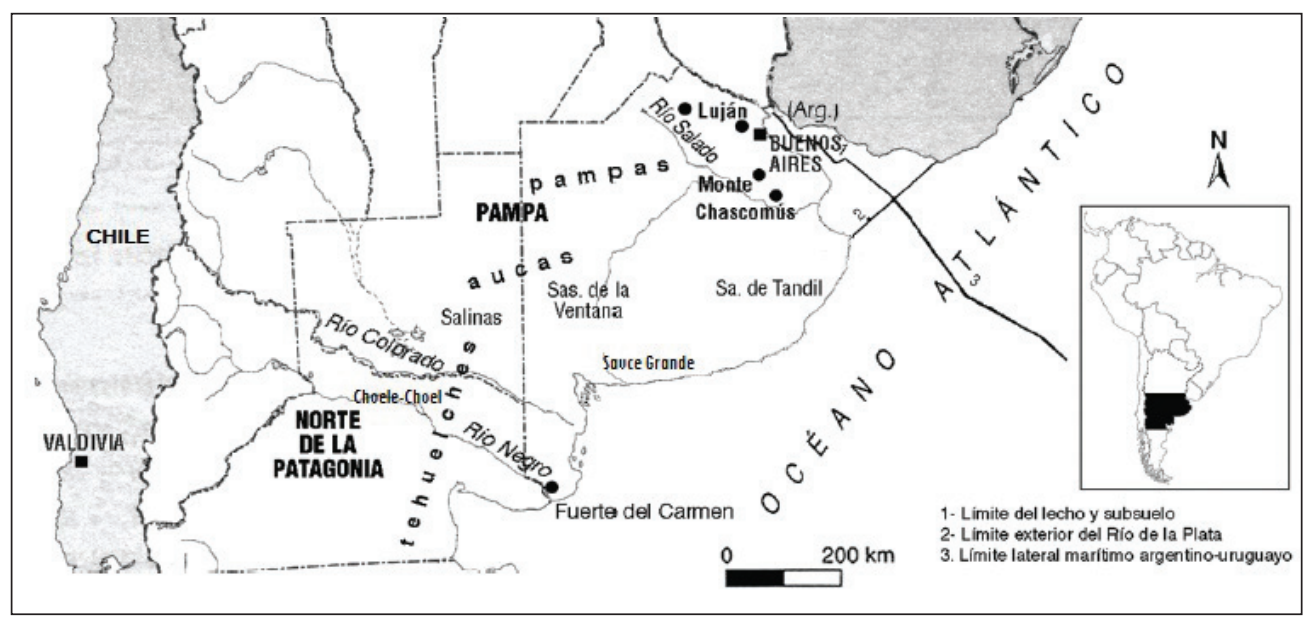

Figura 1: La región en estudio con ubicación de los grupos étnicos.

En relación con lo expuesto, entendemos el paisaje como una construcción social históricamente determinada. En este marco observamos que la idea de «indio» como categoría colonial (Bonfil Batalla 1972) en el contexto anteriormente descrito, no sólo se encontraba estrechamente vinculada con los preconceptos de «salvaje» y «nómada» ${ }^{4}$ sino que también se enlazaba con la idea de «desierto» (Wright 1998), como continuum de la tierra inhóspita. Es por esto que buscamos indagar las formas por las que los expedicionarios virreinales de fines del siglo XVIII se apropiaban simbólicamente del paisaje norpatagónico.

Esta forma de conquista, aunque en el contexto de los viajes de Cristóbal Colón, ha sido estudiada por Todorov (1998), quien ha señalado el uso de analogías relacionadas con lo que los funcionarios conocían de Europa y el interés por nombrar lo desconocido. En nuestro caso, observamos que los expedicionarios de fines del siglo XVIII que recorrieron el norte de la Patagonia, aludían a especies vegetales y

narios habrían buscado facilitar la convivencia y el trato pacífico con los indígenas más que delimitar las agrupaciones; y las alianzas y movimientos de los grupos indígenas se habrían organizado en relación con la accesibilidad a la frontera de Buenos Aires y al ganado cimarrón.

4 Estas asociaciones sostenidas por autores como Canals Frau, Casamiquela, Vignati, Escalada y Harrington, entre otros, fueron criticadas por Nacuzzi $(1991,1998)$. 
animales ajenas a este espacio, propias de Europa y regiones adyacentes, tales como dátiles, leones y perdices. Los viajeros también expresaban analogías con respecto a ciertos aspectos del terreno que resultaban visualmente semejantes a características de edificaciones europeas. De esta manera, podían establecer nexos con otros rasgos del territorio que los potenciales lectores de los documentos pudieran reconocer, lo que permitía a los viajeros brindar una mayor comprensión del espacio norpatagónico a las autoridades virreinales. Por ejemplo, en un diario de 1781, Viedma (1938b: 533) describe unas llanuras que eran atravesadas por un río desde el cual se desprendían cursos menores, «de modo que viene a ser como otro Nilo, que fecunda sus terrenos con las inundaciones». En relación con esto, observamos que los expedicionarios denominaban ciertos lugares con términos asociados principalmente a las formas que percibían en el paisaje con el objeto de optimizar la orientación en los territorios ignotos. El relato de 1782 de Zizur (1910: 232), por ejemplo, alude a que el nombre «Laguna del Monte» se debía a que ésta tenía una isla con arbustos en el centro. Además, los viajeros imponían nombres a ciertos lugares que consideraban carentes de los mismos o que pretendían renombrar. Así, Baygorri de las Fuentes (1778: f1v) narra que, al hallar unas lagunas «sin nombre», las llamaron «del Pilar», y que al pasar por una cañada la nombraron «de Vértiz» (Baygorri de las Fuentes 1778: f1v).

Con el objeto de aclarar su ubicación geográfica, los expedicionarios también comparaban esos topónimos con los de un viaje previo del jesuita Falkner quien ya los había reseñado y servían de referentes. No obstante, estos vocablos no siempre coincidían con los que usaban los indígenas; por ejemplo, según Villarino en su diario de 1782-1783 (1972b: 1015), Falkner llamaba «Laguna del Límite» a lo que los indígenas conocían como Huechun-lauquen.

También encontramos por parte de los viajeros otros términos que remiten a las interpretaciones de los topónimos indígenas. Por ejemplo, en su relato de 1770, Hernández (1910: 551) señala que encontraron «un gran río, el que pasamos casi a nado, y está tan poblado de sauces muy grandes y gruesos, que por eso le dan el nombre de los Sauces». Poco después expone que «a este paraje se le daba el nombre de Ventana, siendo cierto que todas las piedras tienen a su remate muchas quebradas, por donde entran y salen a uno y otro lado de las pampas» (Hernández 1910: 551). Por su parte, Viedma (1779: f144) detalla que los indios llamaban «Río Grande» al río Colorado debido a su caudal, lo cual era relevante destacar en el nombre del lugar ya que condicionaba el cruce del curso de agua.

Resulta notable la utilización de términos indígenas por parte de los expedicionarios para referirse a determinados sitios debido a que evidenciaría que se veían forzados a usarlos para poder orientarse, ya que desconocían el terreno. Generalmente, los viajeros eran guiados por indígenas y adoptaban los nombres que estos utilizaban para referirse a ciertos lugares, interpretando el sentido de las denominaciones y asociando los significados conferidos tanto a rasgos físicos particulares como a amplias regiones. Así, los funcionarios virreinales adoptaban los vocablos que oían decir a los indios que encontraban en cada zona, aunque otros grupos indígenas nombraran de modo distinto al mismo sitio como consecuencia de que los vinculaban estrechamente al lugar donde los hallaban. 
Notamos que la elección y el uso de determinados topónimos como forma de orientarse durante las travesías, respondían a lo que Bender (1993) se refirió como paisajes en tensión -landscapes in tension-, en relación con la polisemia y el dinamismo característicos del fenómeno del paisaje. En este sentido, entendemos que el paisaje constituye la manifestación de las percepciones y los usos de los territorios que los actores sociales llevan a cabo; así es apropiado y cuestionado por quienes utilizan el espacio geográfico. A partir de esto nos aproximamos a los modos en que los expedicionarios percibían los territorios, en relación con el conocimiento del mismo que tenían a través de informantes u observaciones previas. El hecho de renombrar los sitios o de recurrir a términos indígenas, se vinculaba con los intereses puestos en juego en las relaciones interétnicas. Por ejemplo, en diarios de 1781 y 1786, Zizur (1973: 71) apelaba a ciertos nombres con los cuales los indios llamaban a diversos sitios para ubicarse en el territorio, tales como «Másanaguida» para referirse a la «Sierra de la Mesa» y el arroyo y la sierra «Guaminí» (Zizur 1910: 231). Consideramos que el uso de vocablos indígenas por parte de los funcionarios virreinales que describían los lugares y recursos del norte de la Patagonia evidenciaba las relaciones de poder que se plasmaban en el territorio. Por ello reflexionamos acerca de la utilización de recursos clave, no sólo con respecto a los hispanocriollos sino también en relación con los indígenas. Como veremos luego, las percepciones de los viajeros sobre los saberes de los indios acerca de la disponibilidad de los recursos y de las diversas modalidades en el manejo de los mismos, darían cuenta de un conocimiento diferencial del territorio que experimentaban los distintos grupos.

\section{El manejo indígena del territorio desde la perspectiva hispanocriolla}

En los documentos trabajados podemos observar cómo los relatos analizados remarcan una idea de salvajismo vinculada a las «características inherentes» a los indígenas. Al respecto, Luiz (2006) ha planteado que las nociones de «bárbaro-infielsalvaje» eran utilizadas para caracterizar a los grupos resistentes al dominio colonial. Como ejemplo de esto hallamos una pormenorizada descripción de los indios 'pampas' y 'aucaces' realizada por el capitán Hernández (1910: 561) -en un apartado al finalizar su relato de viaje de 1770-, en el que detalla que serían de estatura mediana, robustos, de cara ancha y abultada, ojos sanguinolentos, cabello lacio y grueso, y se vestían con «muchos cueritos de zorrillos, pedazos de león y otros de venado, los que van ingiriendo». Además, narra las actividades que llevaban a cabo los indígenas y que captaban su atención, por ejemplo, el hecho de que por la mañana, al despertarse, fueran a la laguna o río más cercano y se echaran «unos a otros gran porción de agua en la cabeza» (Hernández 1910: 562). Teniendo en cuenta lo expuesto acerca de las asociaciones hispanocriollas sobre los indígenas y lo salvaje y repulsivo, observamos cómo este capitán también refleja el modo de alimentarse de los indios con «cuanto animal encontraran» (Hernández 910: 562). Así describe la caza de un venado que «principalmente procuran para almorzar» al cual «bolean» y luego golpean hasta que caiga al suelo, donde 
«lo degüellan, no permitiendo que le salga sangre alguna, sino que se le vaya introduciendo todo por el garguero, y medio vivo lo abren por entre las piernas, cosa que quepa la mano, y echándole afuera todas las tripas, sacan la asadura entera y se la comen como si estuviera bien guisada, sorbiéndole el cuajo, como si fuera un pocillo de chocolate» (Hernández 1910: 562).

Así, con el énfasis en la ingesta de la carne cruda y el gusto de los indios por ella, Hernández explica el hecho de que las incursiones indígenas en las fronteras bonaerenses no fueran percibidas con antelación, ya que «como no necesitan de fuego para comer, se introducen con facilidad».

De manera semejante, Francisco de Viedma (1779: f142) subraya la pobreza y mansedumbre de los nativos al encontrar: «bastantes tolderías de indios, ya de nación tiguelchus, y ya de pampas llenos de infelicidad, y miseria, y sólo piden de comer por la desdicha en que se ven: sin gemir manifiestan ser dóciles». Paralelamente, resalta el papel de los españoles como benefactores de quienes, desde su punto de vista, eran indígenas famélicos. Sin embargo, a pesar de esa supuesta filantropía hispanocriolla, Viedma (1779: ff148-149) no descuidaba sus intereses por mantener al mínimo los gastos cotidianos, ya que

«todas estas gentes no comen más, que carne de caballo; y más haberles robado los aucaces parte de la caballada, se hallan muy hambrientos, y nos consumen algunos bastimentos, pues por tenerlos gratos al cacique Negro y sus parientes, tengo los más días, que traerlos a bordo, a comer, y darles así más, y porotos para sus familias, bien que todo lo hago con aquella economía posible».

Por otro lado, Viedma (1779: f149) recalca el carácter irritable y la insatisfacción frecuente que él observaba en los indios, lamentando que «el aguardiente es lo que más apetecen con tanto exceso, que no hay fuerzas, porque son insaciables en este vicio, y como no tienen más fe, que mientras se les da, y en faltándoles se enojan». De un modo semejante, Terrada (1808: f 1) señala el «espíritu nocivo que había reconocido en los indios». No obstante, a pesar del énfasis en el salvajismo de los indígenas, en un fragmento de lo escrito por Villarino en 1783, es posible entrever que los indios percibían a los viajeros en una situación más penosa que la propia. De esta manera, podemos observar cómo se forjaban paralelamente las construcciones identitarias mutuas (Barth 1976). En este sentido el piloto expone:

«Me ponderaron estos indios su pobreza, y el dolor que tenían en que sus fuerzas no pudiesen contribuir a mi alivio y al de toda la gente: y así éstos como los peguenches que vinieron esta mañana, viendo los marineros desnudos con frío excesivo metidos en el río, arrastrando las embarcaciones decían lastimándose: «pobres soldados», en su idioma» (Villarino 1972b: 1091-1092).

Retomamos entonces lo expuesto acerca de las relaciones de poder evidenciadas en el empleo de términos indígenas que advertimos en el uso del territorio, especialmente, en relación con el conocimiento diferencial de los grupos con respecto al mismo. Por ejemplo, Hernández (1910: 555), que realizaba su expedición acompañado por un grupo de indígenas, comenta que «queriendo nuestro comandante seguir a las sierras, le previnieron los indios no era posible, por hallarse todo aquel campo sin agua». En contraposición con la ignorancia de los expedicionarios, los indígenas conocían 
el paisaje y no sólo podían escapar fácilmente de los hispanocriollos, encontrar gente y lugares, sino también prever las mejores rutas para avanzar. Así, en su diario de 1782-1783, Villarino (1972b) relata que el cacique Chulilaquin había enviado a dos esclavos suyos para averiguar dónde estaban unos marineros hispanocriollos que no aparecían. En otro caso, Viedma (1938a: 379) lamenta la deserción de un esclavo que le habían comprado al cacique Negro, ya que conocía la región y al fugarse se había llevado cuatro caballos y frioleras de los soldados.

Los modos en que los hispanocriollos aludían a los recursos y a su uso por parte de los indios, nos permiten aproximarnos a las modalidades de interacción indígena en el paisaje. Por ejemplo, Hernández (1910: 548) menciona unas «bolas potriadoras y sueltas, que llaman los indios sacay» y el hecho de que «los indios llaman al pescado challua» (Hernández 1910: 550). Por su parte, Villarino (1972b: 1130) reseña vocablos indígenas tales como «daal»-fruta del chañar-, «Yajaunaujén»-para designar el «Cerro de la Imperial»-(Villarino 1972b: 1096), la loma de «Choelechoel» (Villarino 1972b: 985). Este piloto también señala que «el anta se llama entre los guilliches 'haleglique', y el pellejo 'ysanam'» (Villarino 1972b: 1117).

En este contexto consideramos relevante indagar en la disponibilidad y el uso de recursos, que resultaban claves tanto para indígenas como para hispanocriollos. Siguiendo a Nacuzzi (2002), leemos «entre líneas» ciertas menciones a objetos hispanocriollos entre los indios, al uso de vocablos españoles y algunas resignificaciones de elementos de los «otros» en la vida social indígena.

Al respecto, Palermo (1986) sostiene que el ganado ovino criado por los indios era de interés para los hispanocriollos, ya que poseía mayor corpulencia y vellón más largo en comparación con el de los estancieros bonaerenses. Teniendo en cuenta el amplio desarrollo de los textiles artesanales por las parcialidades indígenas, así como las mayores necesidades de cuidado que requieren las ovejas con respecto a otros ganados, «la posesión de majadas de ovinos indicaría también aquí la adquisición de conocimientos sobre su cría, vinculada con la alimentación y los textiles» (Palermo 1986: 166). Asimismo, junto al ganado vacuno, el caballo constituyó un bien preciado por los grupos indígenas. Desde el punto de vista de Quijada (2002b), se habría alentado el comercio como una estrategia política para mantener relaciones pacíficas en los espacios de frontera. Dicha autora señala que la creciente necesidad de productos de los «blancos» por parte de los indios, y la organización en torno a los arreos de ganado pampeano para los mercados chilenos, se acompañó, paralelamente, por el incremento del consumo de manufacturas indígenas -textiles, objetos de plata- y materias primas - plumas de ñandú, pieles de guanaco, cueros vacunos- por parte de la sociedad «blanca».

En relación con lo expuesto, encontramos en los documentos indicios acerca de las estrategias de los indígenas con respecto al ganado que llevaban las expediciones. Por ejemplo, en un informe de 1781, el superintendente Viedma (1938b: 507) narra que unos peones habrían descubierto «tres caballos orejanos ${ }^{5}$ los que desconocieron por cuyo motivo recelaba si eran de indios que se les habría venido» y que un oficial

\footnotetext{
5 Según la $22^{\circ}$ edición del Diccionario de la Real Academia Española, una res orejana no tiene marcas en las orejas ni en otras partes del cuerpo.
} 
bajo su mando habría logrado recuperar unos bueyes extraviados, de los cuales «solo faltaba uno que mataron los mismos indios porque decían estaba espiado ${ }^{6}$, y no podía caminar. Aseguran los encontraron inmediato al río Colorado, y los recogieron para volverlos al establecimiento del río Negro» (Viedma 1938b: 514-515).

El piloto Villarino destaca la utilización de caballos reyunos ${ }^{7}$ por los indios y señala la tenencia y distribución de haciendas por parte de los caciques. Por ejemplo, describe que el cacique Cuyupilqui le habría asegurado que lo acompañaría hasta Valdivia, franqueándole caballos para el viaje, y que cuando el viaje concluyese, regresaría río abajo con él, y sus indios por tierra, para conocer el establecimiento del río Negro. Villarino (1972b: 1025) ${ }^{8}$ sostiene que de esta manera intentaría desde allí «pasar a las pampas de Buenos Aires a tomar ganado vacuno y caballar para su provisión y mantenimiento, y vender en Valdivia». No obstante, el cacique Cuyupilqui habría manifestado que él no causaba perjuicios ya que tomaba el ganado «del bagual que andaba en el campo: que cuando venían de sus tierras, venían con muy pocos caballos, pero que traían ponchos y otras cosas, con las cuales hacían trato con los indios del Volcán, por caballos para correr en la pampa» (Villarino 1972b: 1025).

También Hernández (1910) se refiere a las posesiones de ganado indígena, señalando que el cacique Lincon tenía sus tolderías próximas a las del cacique Alcaluan, quien mantenía una majada de ovejas y cabras. Por su parte, en el relato de 1781, Zizur (1973) menciona con frecuencia la presencia de ganado vacuno y yeguada en los campos que atravesaban, los cuales supone que «pertenecerían» a los indios. De manera semejante, Viedma (1938b) detalla que el peón Godoy le había informado que los ranqueles tenían ovejas, cabras, y gran cantidad de yeguas y caballos.

En consecuencia es necesario tener en cuenta no sólo la disponibilidad de los recursos sino también el modo en que se utilizaban los mismos y su territorio. En relación con esto, analizamos en los documentos lo propuesto por Nacuzzi (1991) sobre las denominaciones de los sitios escogidos por los indígenas como «paraderos» asociados con las ventajas naturales -tales como disponibilidad de agua dulce, leña, pasturas o refugio- o de rasgos topográficos característicos. Por ejemplo, para Villarino (1972b: 1066) no era sorprendente hallar indicios de que algunos indígenas habían estado en un «potrerito chico que tiene el río por la parte del norte, y así sucede en todos, porque no hay rincón por chico que sea a la orilla del río, como tenga algún pasto, que no esté trillado y pisoteado de ellos». Los diarios de Viedma (1779: f 148) muestran que los indios instalaban sus toldos generalmente en sitios donde

\footnotetext{
${ }^{6}$ El término hace referencia a que el objeto está afirmado al suelo por medio de espías -cabos- En otros documentos también se ha hallado el vocablo «despeado» para señalar un caballo al que se le han estropeado los cascos por haber caminado mucho sin herraje, según lo expresaba Villarino (1972b: 987).

7 Según la $22^{\mathrm{a}}$ edición del DRAE el adjetivo «reyuno» se utilizaba en la región rioplatense para referirse a los caballos pertenecientes al Estado, que llevaban como señal la mitad de la oreja derecha cortada.

8 En otra situación, habían indagado a quien se había presentado como Ignacio Delgado, y éste les habría brindado detalles sobre Buenos Aires, Montevideo, Maldonado, Santa Teresa, Santa Fe y Valdivia, informándoles acerca de la distancia hasta Valdivia y de la ubicación de bosques de pinos. El indígena habría contado, además, «que tenía vacas, y que entre los indios había bastante de este ganado, caballar y lanar; que en llegando cerca de sus toldos haríamos trato con algunas vacas» (Villarino 1972b: 1091). Luego el piloto aclara que «contestan muchos ios en que Ignacio Delgado es cacique, y hombre de mucha hacienda; este vive a la orilla del río Catapuliche, un poco más arriba del desagüe de Huechu-huechuen, en dicho Catapuliche» (Villarino 1972b: 1094).
} 
había fuentes de agua permanentes: el cacique «Chanen: tiene muchas tolderías, que las más de ellas han hecho su asiento a la margen del río por la parte del norte, y en el día llegaron a cerca de treinta». En otra ocasión, el cacique Calpisquis mandó al peón Godoy con sus indios a los toldos de los raqueles, quienes después de atravesar la sierra de la Ventana

«encontraron dos cerros, y por medio de ellos hay un arroyo de muy buena agua, [...] y pasado hallaron camino abierto hasta los toldos: Que como unas seis a siete leguas de estos cerros hay unos médanos de arena muy altos, y tendrán dos leguas de ancho, de cuyo paraje tienen tres pozos abiertos, inmediato a una laguna de agua llovediza» (Viedma 1938b: 540).

En este último ejemplo observamos que los sitios escogidos para obtener agua se encontraban en lugares fácilmente distinguibles por una razón en especial, en este caso en particular, las dimensiones de los médanos y su cercanía con los cerros citados. Los modos en que se utilizaban los recursos y el territorio, tanto por los indígenas como por los hispanocriollos, se veían influenciados mutuamente como consecuencia de las interacciones entre los grupos. Como veremos en el próximo epígrafe los viajeros adoptaron ciertas modalidades de manejo indígena del espacio norpatagónico.

\section{Influencias en los usos del territorio por parte de indígenas y expedicionarios}

En las estrategias de utilización del espacio es relevante destacar la importancia de la movilidad de los grupos, ya que respondían a modos tanto indígenas como hispanocriollos, aunque con características diferentes. Los diarios de viaje de los expedicionarios dan cuenta de la movilidad hispanocriolla, que necesariamente adoptaba ciertos rasgos del manejo indígena del territorio bajo su control. La posibilidad de la circulación por el territorio resultaba fundamental para los grupos indígenas, particularmente en lo que respecta al abastecimiento de recursos para la subsistencia (Nacuzzi y Pérez de Micou 1994). Este hecho se encuentra mencionado en el relato de Hernández (1910: 563), quien detalla la constitución de las viviendas y da cuenta de la alta movilidad de las agrupaciones:

«Las casas o poblaciones son de estacas de tres varas, y cueros de caballos por los lados y techos, que ellos les llaman suca y nosotros toldos ${ }^{9}$. En cada uno vive una familia, y en medio de dichos toldos tiene el cacique su habitación, la que no es fija, pues en un paraje viven un mes, en otros quince días o veinte, con cuyo motivo es difícil dar con ellos»».

Consideramos pertinente, para los demás grupos indígenas estudiados en este trabajo, el patrón de movilidad propuesto por Nacuzzi (1991) para los tehuelches, dado que todos ellos planeaban sus movimientos y la obtención de determinados recursos

\footnotetext{
9 Nacuzzi (2008) ha definido el «toldo» como una vivienda principalmente ocupada por una familia nuclear, construida con palos y cueros que permitían desarmarla para transportarla con mayor facilidad. Estas unidades se agrupaban en «tolderías» o «toldos» con distintas dimensiones y funciones dependiendo de los objetivos buscados: campamento base, asentamientos próximos en áreas de aprovisionamiento, asentamientos transitorios, grandes asentamientos mixtos (Nacuzzi 1991).
} 
económicos con antelación, previendo los desplazamientos por rutas conocidas en las que se identificaban ciertos puntos con nombres significativos. En este sentido, consideramos el nomadismo como «una estrategia económica que buscaba maximizar las posibilidades económicas y no estaba restringido a las actividades de caza» (Nacuzzi 2007: 227).

En contraposición con el conocimiento indígena del territorio, observamos indicios del desconocimiento del paisaje por parte de los hispanocriollos, que se reflejaba en las diferentes modalidades escogidas para estimar las distancias y duración de las jornadas de viaje. En el caso del cálculo espacial, los expedicionarios lo hacían con sistemas métricos europeos y los indígenas en días de caminata entre un lugar y otro. Por ejemplo, Villarino (1780: f11) declara que habían oído gritar unos pájaros «a dos cuadras de distancia» y había mandado a revisar al día siguiente desconfiando que hubiese sido gente, a raíz de lo cual hallaron «el rastro de tres caballos adonde habían dormido distancia media legua de nosotros» (Villarino 1780: f11). En un diario posterior, el piloto asegura que los indios de Huechun le habían dicho «que su tierra dista cuatro jornadas de Valdivia; que aunque la distancia es corta el camino es malo; que se pasa la Cordillera por el Portillo; que la tierra del cacique Cangapol nos queda dos días de jornada aguas abajo» (Villarino 1972: 1018).

De manera semejante, encontramos ejemplos de mediciones indígenas del tiempo efectuadas en cantidad de lunas que al parecer habrían adoptado los expedicionarios. Por ejemplo, Villarino (1779: f10v) relata que se había encontrado con un cacique al que le había dicho que «iba a buscar qué comer que ya no tenía, y que en una luna me esperase que lo regalaría». También el superintendente Viedma (1781: flv) explicita que los indígenas medían el tiempo en lunas y los hispanocriollos en días, señalando que los indios se habían marchado después de que les pagaran por el ganado y los caballos, ofreciéndose «a la siguiente luna traer más ganado». El modo indígena de concebir el tiempo también puede observarse en otro de los diarios del superintendente, quien escribía que «había otro cacique poderoso llamado Sn Quil, el que había de ir a visitarle con el cacique Negro, dentro de pocas lunas» (Viedma 1938b: 531).

Viedma proporciona también indicios de que para los hispanocriollos resultaba más práctico hacer referencia a días de viaje en caso de no poder recurrir a sistemas de medición europeos. Por ejemplo, unas cautivas le informaron que el cacique Guchulap estaba acampado con su gente a «dos días de camino distante de estos toldos [los del cacique Calpisqui], en un paraje inmediato a las Salinas donde vienen por sal desde Buenos Aires con carretas y tropas» (Viedma 1938b: 517-518, el destacado es nuestro). Poco después, Viedma da otra muestra de la preferencia de los expedicionarios por las alusiones al trayecto en cantidad de jornadas, al señalar que:

«desde el Cholechen salen dos caminos que va expresado están dos jornadas de él, donde hay agua en abundancia, y desde este paraje sigue el camino del Sauce y sierras referidas, y algunas indiadas le suelen transitar sin hacer parada en el Colorado que los terrenos de este río y los del cacique Negro y sus indios» (Viedma 1938b: 531-532, el destacado es nuestro).

En relación con los distintos grados de conocimiento del territorio por parte de los grupos indígenas y de los funcionarios coloniales, ponemos también en evidencia sus implicaciones en la correspondencia entre los objetivos de las misiones y los 
resultados obtenidos. De esta manera, los expedicionarios intentaban solventar su desconocimiento sobre la región mediante la planificación de acciones ofensivas y defensivas, para lo cual se esforzaban en averiguar datos acerca de la organización de las agrupaciones indígenas. Así, puede observarse repetidas veces en los relatos menciones la cantidad de indios en cada toldo y la proporción entre ellos de hombres capaces de guerrear. Por ejemplo, Hernández (1910: 548) expone que «el número de indios que estos caciques llevaban, se componía de doscientos noventa y uno: los ciento veintitrés de lanza, y el resto de bolas potriadoras y sueltas». En el caso de Viedma (1938b: 511) envió dos peones a la sierra de la Ventana llevando cuatro barriles de aguardiente para los caciques Calpisquis, Toro, Guchulap, y Chanel, para que reconocieran «con prolijidad a aquellos terrenos, y todo el camino que anduviesen qué número de tolderías habría, cuántos caciques, y últimamente todas aquellas advertencias que me parecieron útiles para mi gobierno, y el mejor modo como se debían manejar con los indios»».

Villarino (1972b) destaca que había hallado sólo seis chinas en una población de trescientos indígenas y, gran parte de los demás, sólo arreaban o cazaban. En este sentido, observamos que los funcionarios gubernamentales hallaban escasas mujeres durante sus travesías, ya que éstas no asistían a las reuniones interétnicas o se ocultaban ante circunstancias de tensión. A partir de la distinción entre tipos de asentamientos según la finalidad del movimiento, Nacuzzi (1991) ha planteado la existencia de «campamentos base» donde permanecían las mujeres, niños y ancianos, mientras los hombres iban a cazar o a partidas de intercambio. Acerca de esta distribución diferencial de los individuos, Hernández (1910: 557) comenta que sólo habían logrado capturar once indias ya que como «dichos teguelches [...] no estaban de asiento, sino en el servicio de potrero, habían dejado sus familias al otro lado del río Colorado». Asimismo, resulta interesante observar, en las alusiones a las mujeres, aspectos que traslucen las distancias culturales implícitas, tales como el trato interpersonal ${ }^{10}$. En relación con esto notamos el modo en que Hernández (1910: 563) describe la circulación de mujeres entre los indígenas:

«Cada uno tiene las mujeres que pueda comprar, y viéndose aburrido de ellas las vende a otros; y si llegan a tomar algunas cautivas, luego que llegan a sus toldos se casan con ellas: y si dichas cautivas, más que sean indias, no van contentas, luego las lancean y las arrojan del caballo, y aunque estén medio vivas, las dejan».

Se evidencian aquí algunas de las razones por las cuales gran parte de los expedicionarios se esforzaban por lograr la devolución de cautivos, a fin de evitar que las mujeres hispanocriollas se vieran sometidas a los intereses indígenas.

10 Hernández (1910: 563) también distingue entre labores efectuadas por los indígenas según su sexo: «El trabajo de ellos se reduce a tomar yeguas y potros silvestres, cazar zorrillos, leones, tigres y venados, de cuyas pieles hacen las indias quiapís y guasipicuás, y de las plumas de avestruz hacen plumeros, siendo ellas [las mujeres] las que todo lo trabajan, pues les dan de comer, cargan las cargas, mudan los toldos y los arman: y aunque las vean los indios, quienes están echados de barriga, no se mueven a ayudarlas en nada; antes sí, si es poco sufrido, se levanta, y con las bolas que nunca las dejan de la cintura, le dan bolazos, y a esto no llora ni se queja la india». 
Los funcionarios y viajeros anotaban frecuentemente en sus diarios informaciones sobre intercambios de cautivos y datos sobre en qué tolderías podría haber otros no registrados. En sus respectivos relatos de 1779, tanto Viedma como Villarino se refieren a individuos en poder de los indígenas. Por ejemplo, Viedma (1779: ff144-145) menciona que el cacique Negro le había llevado «una niña cristiana cautiva de las chacras de Buenos Aires y dos negros del mismo paraje» y Villarino (1972a: 685) señala que había llegado «el marinero que faltaba, al cual lo habían apresado los indios en los toldos, y tenían ya como esclavo».

No sólo existen noticias de cautivos en poder de los indígenas, también pueden vislumbrarse datos sobre ciertos indios que vivieron con los hispanocriollos, sin que quede completamente clara la obligación o no que habrían tenido de permanecer allí. Por ejemplo, en su informe de 1781, Viedma (1938) escribe que la india ladina Juana, sobrina del cacique Calpisquis, le había dicho que había estado en la residencia de Buenos Aires y en la casa del teniente del rey, pero no explicita que grado de elección había tenido la mujer.

La información más abundante se refiere a los intercambios de personas entre los expedicionarios y las distintas parcialidades indígenas, más que a la cantidad de prisioneros en poder del bando opuesto, ya que los expedicionarios suponían siempre una mayor cantidad de cautivos que los que veían -los cuales habrían sido ocultados ad hoc ante su cercana presencia-. Por ejemplo, Villarino (1780: f13) da cuenta de haber encontrado rastros de indios en la playa, particularmente «las pisadas de niños frescas como de esta mañana o de ayer». En este sentido, es preciso tener presente que los indios respondían a sus propias intenciones antes que a las de los miembros de la expedición -v. gr., pasando la noche en el campamento de la comitiva en lugar de hacerlo en sus toldos (Villarino 1972b)-. Además los indígenas contaban con cristianos entre sus huestes, quienes les ayudaban a obtener beneficios en cuestiones que no manejaban completamente. Por ejemplo, Viedma (1938b: 521-522) relata que unas cautivas habrían revelado que había un cristiano en los toldos que estaba

«bombeando y bicheando en todos los pagos de las fronteras de Buenos Aires donde tienen más ganado, donde hay más descuido, y buenas mozas, y en fin es el único confidente y baqueano que tienen los indios para su entrada y robos, sin el cual no pueden hacer nada con acierto».

Viedma reseña sus posteriores indagaciones sobre ese individuo que colaboraba con los indios y dificultaba a las poblaciones de la frontera de Buenos Aires permanecer a resguardo. Así, le habían informado que este personaje «usaba vestido completo de cristiano con lo que no lo echan de ver ni es conocido entre los nuestros, y que este mal hombre nos hace más daño que todos los indios juntos, pues si les faltara no habían de dar sus avances tan seguros» (Viedma 1938b: 536).

Pero los hispanocriollos no siempre colaboraban con agrado con los indios, sino que debían atenerse a las circunstancias a fin de salir airosos. En este sentido, Viedma (1938b: 520) rememora que dos hombres habían sido perseguidos por los indígenas, quienes al apresarlos, habían matado a uno «y al otro llevaron tierra adentro, no se sabe en qué paraje, que éste que quedó vivo tenía una pistola y enseñaba a los indios, cómo se tiraba». 


\section{Consideraciones finales}

A lo largo de este trabajo hemos analizado, desde una perspectiva etnohistórica, cómo los expedicionarios que recorrieron el norte de la Patagonia a fines del siglo XVIII percibieron las estrategias indígenas de manejo de los recursos y los territorios que habitaban.

Hemos presentado el uso de vocablos indígenas para aludir a ciertos topónimos y recursos por parte de los viajeros como un reflejo de las relaciones sociales implícitas en el paisaje. Asimismo nos hemos centrado en la utilización de determinados recursos que resultaban importantes, tanto para los indios como para los hispanocriollos, especialmente el ganado. Hemos estudiado tanto la disponibilidad de los recursos como las modalidades de uso de los mismos y su territorio, teniendo en cuenta el contexto de enunciación del discurso que se plasma en los documentos (Nacuzzi 2002), con el objeto de comprender no sólo las perspectivas hispanocriollas sino también las indígenas.

De esta manera, observamos que las representaciones de los expedicionarios acerca del paisaje reflejan también los modos de percibir a los grupos indígenas que habitaban esos territorios. Paralelamente los indígenas generaban sus propias ideas sobre los hispanocriollos afectando las percepciones de estos. Advertimos que los indios entendían que los expedicionarios se encontraban en una situación más lamentable que la propia, y si bien los indígenas eran vistos por los viajeros como «bárbaros»e «infieles», en la práctica los hispanocriollos necesitaban de sus saberes y permisos para poder transitar las áreas desconocidas.

Además, otorgamos relevancia a la movilidad de los expedicionarios y no sólo a la de los indígenas, que generalmente había sido realzada en detrimento de la primera en relación con las asociaciones historiográficas tradicionales entre el nomadismo y el salvajismo. Pensamos que la movilidad que definía a los viajeros hispanocriollos se presentaba desdibujada aunque, en la mayoría de los casos, evidenciaba menores grados de previsibilidad y de conocimiento sobre el territorio que los que exhibían los indios.

En relación con lo expuesto, señalamos la relevancia del contexto de los relatos de viaje implícita en las imágenes sobre el paisaje, que lleva a encubrir la semejanza entre los modos de obtener víveres desarrollados por los indios y por los funcionarios coloniales. Por ello, consideramos que el conocimiento diferencial sobre el territorio evidenciado en las representaciones y usos llevadas a cabo por los diferentes grupos, resultaba una herramienta a disposición de los indígenas que podían aprovecharla como estrategia para obtener ciertas ventajas. Así, durante el periodo tardocolonial, el conocimiento indígena de la región constituía una herramienta que confería poder a quien la manejara, y era conscientemente aprovechada por los indios en sus relaciones con otros grupos tanto indígenas como hispanocriollos. Paralelamente, los relatos de los funcionarios coloniales sobre el interior norpatagónico, se conformaron como instrumentos hispanocriollos de saber, útiles para comprender las dinámicas territoriales en una región bajo dominio indígena y pensar estrategias de control de los grupos sociales. No obstante, las prácticas de las distintas sociedades siempre es- 
tuvieron condicionadas por las interacciones con los «otros» y las respuestas de éstos afectaron el desarrollo de los contactos interétnicos.

El desconocimiento de los viajeros respecto del paisaje y de la organización de las parcialidades indígenas, también se manifestaba en el logro relativo de los objetivos propuestos por las expediciones y en la necesaria adaptación de los hispanocriollos a los cambios circunstanciales como consecuencia de los errores cometidos, como por ejemplo, la escasa recuperación de cautivos. Como mostramos, estas dificultades a las que se vieron enfrentados los expedicionarios como consecuencia de su desconocimiento del territorio se contraponían al manejo indígena de los recursos de la región.

Agradecimientos: A la Dra. Lidia Nacuzzi por su atenta lectura y los comentarios críticos sobre el manuscrito. Este trabajo fue realizado con el apoyo de los subsidios otrogados por la Universidad de Buenos Aires (UBACyT F105) y el Consejo Nacional de Investigaciones Científicas y Técnicas (CONICET PIP 0026).

\section{Referencias documentales}

\section{Baygorri de las Fuentes, José Antonio}

1778 Diario $[\ldots]$ en que se da noticia de la expedición y destacamento que [...] marchó al campo del enemigo reconociéndolo hasta llegar a las Salinas. Colección de Manuscritos de De Angelis en la Biblioteca Nacional de Río de Janeiro: I 29, 9, 61.

TERRADA, Juan Ignacio

1808 Diario de la expedición a Salinas. Biblioteca Nacional de Río de Janeiro: I 29, 11, 19.

VIEDMA, Francisco

1779 Informe de don Francisco Biedma sobre el Carmen de Patagones. Archivo General de la Nación, Biblioteca Nacional: Legajo 196.

1781 Continuación del diario de los acontecimientos y operaciones del nuevo establecimiento del Río Negro en la costa Patagónica desde $1^{\circ}$ de octubre de este año hasta el día ultimo de su fecha. Archivo General de la Nación: Buenos Aires 327.

VilLARINo, Basilio

1779 Diario de la descubierta al Río Colorado. Archivo General de la Nación, Biblioteca Nacional: Legajo 167. Colección Félix Frías.

1780 Diario de los reconocimientos del Río Colorado, Bahía de Todos los Santos, e internación del Río Negro. Archivo General de la Nación, Biblioteca Nacional: Legajo 167. Colección Félix Frías.

\section{Referencias bibliográficas}

BARTH, Frederik (ed.)

1976 «Los grupos étnicos y sus fronteras. La organización social de las diferencias culturales. México: Fondo de Cultura Económica. 
BAYón, María y Alejandra PuPIO

2003 «La construcción del paisaje en el sudoeste bonaerense (1865-1879): una perspectiva arqueológica», en Las fronteras hispanocriollas del mundo indigena latinoamericano en los siglos XVIII-XIX, R. Mandrini y C. D. Paz, comps., pp. 345-374. Neuquén, Bahía Blanca, Tandil: CEHR, Universidad Nacional del Sur, IEHS.

BENDER, Barbara

1993 «Introduction: Landscape - Meaning and Action», en Landscapes: Politics and Perspectives, B. Bender, ed. pp. 1-17. Oxford: Berg.

BoccAra, Guillaume

2005 «Génesis y estructura de los complejos fronterizos euro-indígenas. Repensando los márgenes americanos a partir (y más allá) de la obra de Nathan Wachtel». Memoria Americana 13: 21-52. Buenos Aires.

Bonfil Batalla, Guillermo

1972 «El concepto de indio en América: una categoría de la situación colonial». Anales de Antropología 9: 105-124. México.

ENRIQUE, Laura Aylén

2010a La percepción del territorio del norte de la Patagonia entre los funcionarios del Virreinato del Rio de la Plata a fines del siglo XVIII. Trabajo de grado de licenciatura inédito. Universidad de Buenos Aires.

2010 b «Usos y representaciones sobre el paisaje del norte de la Patagonia por los expedicionarios de fines del siglo XVIII», en Fronteras. Espacios de interacción en las tierras bajas del sur de América, C. Lucaioli y L. Nacuzzi, comp., pp. 175-203. Buenos Aires: Sociedad Argentina de Antropología.

2010c «Los diarios de viaje de Basilio Villarino como fuentes de información acerca del paisaje norpatagónico», en VI Jornadas sobre Etnografía y Métodos Cualitativos. Buenos Aires: Instituto de Desarrollo Económico y Social.

FoucAult, Michel

1992 Microfísica del poder. Madrid: Ediciones de la Piqueta.

HERnÁNDEZ, Juan Antonio

1910 «Diario que el Capitán D. Juan Antonio Hernández ha hecho, de la expedición contra los indios Tehuelches en el gobierno del Señor D. Juan Jose Vertiz, Gobernador y Capitan de estas Provincias del Río de la Plata, en $1^{\circ}$ de octubre de 7770», en Colección de obras y documentos..., Pedro de Angelis, comp. Tomo IV, Volumen B. Buenos Aires: Librería Nacional de J. Lajouane \& Cía.

IRURTIA, María

2002 «La visión de los indios respecto de los «cristianos» y «huincas» en el norte de la Patagonia, siglos XVIII y XIX», en Funcionarios, diplomáticos, guerreros. Miradas hacia el otro en las fronteras de Pampa y Patagonia, (Siglos XVIII y XIX), L. Nacuzzi, comp. pp. 247-285. Buenos Aires: Sociedad Argentina de Antropología.

LuIz, María

2006 Relaciones fronterizas en Patagonia: la convivencia hispano-indígena del periodo colonial. Ushuaia: Asociación Hanis, Universidad Nacional de la Patagonia San Juan Bosco. 
NACUZZI, Lidia

1991 «La cuestión del nomadismo entre los tehuelches». Memoria Americana 1: 103134. Buenos Aires.

1998 Identidades impuestas. Tehuelches, aucas y pampas en el norte de la Patagonia. Buenos Aires: Sociedad Argentina de Antropología.

2002 «Leyendo entre líneas: una eterna duda acerca de las certezas», en Historias y estilos de trabajo de campo en la Argentina, S. Visacovsky y R. Guber, comp, pp. 229-262. Buenos Aires: Antropofagia.

2007 «Los grupos nómades de la Patagonia y el Chaco en el siglo XVIII: Identidades, espacios, movimientos y recursos económicos ante la situación de contacto. Una reflexión comparativa». Chungará 39 (2). 221-234.

2008 «Repensando y revisando el concepto de cacicazgo en las fronteras del sur de América (Pampa y Patagonia)». Revista Española de Antropología Americana 38 (2): 75-95.

Nacuzzi, Lidia y Cecilia Pérez de Micou

1994 «Rutas indígenas y obtención de recursos económicos en Patagonia». Memoria Americana 3: 91-103. Buenos Aires.

PALERMo, Miguel

1986 «Reflexiones sobre el llamado «complejo ecuestre» en la Argentina». Runa 16: 157-178. Buenos Aires.

QuiJADA, Mónica

2002a «Repensando la frontera argentina: concepto, contenido, continuidades y discontinuidad de una realidad espacial y étnica (siglos XVIII-XIX)». Revista de Indias 224: 103-142.

2002b «A modo de Presentación», en Funcionarios, diplomáticos, guerreros. Miradas hacia el otro en las fronteras de Pampa y Patagonia (Siglos XVIII y XIX), L. Nacuzzi, comp., pp. 9-24. Buenos Aires: Sociedad Argentina de Antropología.

ReAl Academia Española

2001 Diccionario de la Lengua Española. Documento electrónico, <http://www.rae.es/ rae.html>, con acceso en agosto de 2010.

ToDorov, Tzvetan

1998 La conquista de América. El problema del otro. México: Siglo Veintiuno Editores.

VIEDMA, Francisco

1938a «Documento relativo a la expedición de Juan de la Piedra a las bahías Sin Fondo y San Julián, emprendida el 14 de Diciembre de 1778». Revista de la Biblioteca Nacional 2 (6): 364-384. Buenos Aires.

1938b «Diario de Francisco de Viedma, sobre las exploraciones y descubrimientos en las zonas de Río Negro (1781)». Revista de la Biblioteca Nacional 2 (7): 503-552. Buenos Aires.

VILLARINO, Basilio

1972a «Diario de la navegación emprendida en 1781 desde el río Negro, para reconocer la Bahía de Todos los Santos, las islas del Buen Suceso, y el desagüe del río Colorado», en Colección de obras y documentos..., Pedro de Angelis, comp. Tomo VIII, Volumen B. Buenos Aires: Editorial Plus Ultra.

1972b «Diario del piloto de la Real Armada D. Basilio Villarino del reconocimiento que hizo del Río Negro en la costa oriental de Patagonia el año de 1782», en Colección 
de obras y documentos..., Pedro de Angelis, comp. Tomo VIII, Volumen B. Buenos Aires: Editorial Plus Ultra.

Wright, Pablo

1998 «El desierto del Chaco. Geografías de la alteridad y el estado», en Pasado y presente de un mundo postergado. Trece estudios de antropología, arqueología e historia del Chaco y piedemonte andino, A, Terjel y O. Jerez, eds., pp. 35-36. Jujuy: Universidad Nacional de Jujuy.

Zizur, Pablo

1910 «Diario de la expedición a Salinas emprendida por orden del Marqués de Loreto. virrey de Buenos Aires, en 1786», en Colección de obras y documentos..., Pedro de Angelis, comp. Tomo V, Buenos Aires: Librería Nacional de J. Lajouane \& Cía. 1973 «Diario a Sierra de la Ventana 1781», en «Un diario inédito de Pablo Zizur», de M. Vignati. Revista del Archivo General de la Nación 3: 65-116. Buenos Aires. 